\title{
Performance of neck circumference to predict obesity and metabolic syndrome among adult Saudis: a cross-sectional study
}

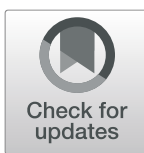

Rasmieh Alzeidan ${ }^{1}$, Amel Fayed ${ }^{2,3^{*}}$ (D, Ahmed S. Hersi ${ }^{1}$ and Hala Elmorshedy ${ }^{2,3}$

\begin{abstract}
Background: Neck circumference (NC) is a novel simple and stable body measurement, a growing body of evidence indicates its validity to diagnose obesity and metabolic syndrome (MetS). Because the cutoff value of NC is gender and ethnic-specific; we conducted the current study to explore the performance of NC to predict general obesity, central obesity, and MetS among adult Saudis of both genders.

Methods: This is a cross-sectional study which included 3063 adult Saudis (1156 males and 1907 females) with a mean age of $38.6 \pm 14.1$ years. Anthropometric measurements and blood pressure were assessed by a standardized methodology. Blood tests including fasting lipid panel, blood glucose, fasting blood glucose and hemoglobin A1c (HBA1C) were measured for all participants. We identified the MetS based on Adult Treatment Panel III (ATPIII definition). Data were analyzed using SPSS 19 (PASW statistics data document 19); NC was compared to relevant anthropometric measures to predict obesity and MetS using Receiver Operator Characteristic (ROC) analyses. The cutoff value of $\mathrm{NC}$ which possessed good discriminating power between obese and non-obese patients was estimated by Youden index, and we estimated the adjusted Odds Ratio (OR) to delineate the association between NC and the outcome variables by multiple logistic regression analysis.
\end{abstract}

Results: ROC analyses demonstrated good performance of NC for general obesity, central obesity and MetS; as a predictor of obesity in non-diabetics, Area Under the Curve (AUC) ranged from 0.77-0.86. In MetS, AUC was 0.77 and 0.82 for males and females respectively. The best cutoff values of the NC to predict obesity were $\geq 37.5 \mathrm{~cm}$ for males versus $\geq 32.5 \mathrm{~cm}$ for females. The results of adjusted logistic regression analysis adjusted for age and waist height ratio, revealed a consistent positive association between NC, general obesity, MetS, and central obesity: ORs were 4.26, 3.03, 1.45 for males versus 4.65, 3.66, and1.47 for females respectively.

Conclusion: NC stands out as an independent predictor of obesity and the MetS. Its stability, easiness of application, low cost and the cultural acceptance, justify its use as a screening tool for general and central obesity as well as MetS among Saudis under community settings, and as an additional routine measurement for health professionals.

Keywords: Central obesity, General obesity, Metabolic syndrome, Neck circumference, Saudi Arabia

\footnotetext{
* Correspondence: fayedam_200@hotmail.com

${ }^{2}$ College of Medicine, Princess Nourah bint Abdulrahman University, Riyadh,

Saudi Arabia

${ }^{3}$ High Institute of Public Health, Alexandria University, Alexandria, Egypt

Full list of author information is available at the end of the article
}

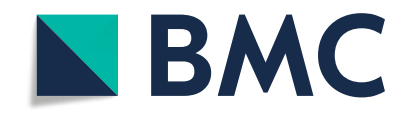

(c) The Author(s). 2019 Open Access This article is distributed under the terms of the Creative Commons Attribution 4.0 International License (http://creativecommons.org/licenses/by/4.0/), which permits unrestricted use, distribution, and reproduction in any medium, provided you give appropriate credit to the original author(s) and the source, provide a link to the Creative Commons license, and indicate if changes were made. The Creative Commons Public Domain Dedication waiver (http://creativecommons.org/publicdomain/zero/1.0/) applies to the data made available in this article, unless otherwise stated. 


\section{Background}

The epidemic of obesity constitutes a world-wide major health problem; its consequences on the occurrence of cardiovascular diseases, type 2 diabetes are major concerns for physicians because of the associated poor quality of life, increased morbidity and mortality [1-5].

In the Kingdom of Saudi Arabia (KSA), the economic transition moving toward more wealth and prosperity has increased the risk of obesity through multiple interplaying factors including changes in dietary habits, and in behavioral factors associated with sedentary lifestyles [6]. Such tremendous lifestyle changes seemed to have fueled the obesity epidemic in the country and resulted in the most rapidly increasing prevalence of obesity in the world [7]. This phenomenon matches the situation observed in other Gulf Cooperation Council (GCC) countries, as well as many other Arab countries [8, 9]. Hence continuous monitoring of obesity is essential to estimate the magnitude of the problem, allocate resources and implement effective interventions.

Validated measures of obesity and body fat include; Body mass index (BMI), the waist-height ratio (WHtR), waist-hip ratio (WHpR), and waist circumference (WC). Except for WC, all of them are computed based on more than one physical body measurements, and the last three should be measured on light clothing, which could be cumbersome in cold weather. Blood tests which measure dyslipidemia, and determine the risks of cardiovascular diseases are invasive and expensive [10]. Advanced highly sensitive diagnostic tools to assess body fat as computed tomography (CT), and magnetic resonance imaging (MRI) are available, yet their application is limited for clinical settings since they are quite costly, and troublesome [11].

Neck Circumference (NC) emerges as a novel, simple, and discrete upper body measurements which differentiates between obese and non-obese. Moreover, several studies demonstrated the validity of $\mathrm{NC}$ as a measure of metabolic syndrome (MetS), as it correlates positively with the classical anthropometric indices such as BMI, WC, and WHtR [12-14]. NC cutoff values varies according to age, gender and ethnic group. For example: among Brazilian adolescence, the cutoff values of NC among overweight boys and girls were 31.25 , and 34.25 $\mathrm{cm}$, and were 32.65 and $37.95 \mathrm{~cm}$, among obese boys and girls respectively [12].Considering variations due to ethnicity; the cutoff for NC among Chinese adolescents is lower than that for the Brazilian adolescents [15].

As a measure of upper body subcutaneous fat (UBSF), NC exhibits a higher metabolic risk than lower subcutaneous fat, and abdominal visceral fat, it correlates positively with free fatty acids, insulin resistance, very-low-density lipoprotein cholesterol (VLDL-C) production, oxidative stress, endothelial cell dysfunction, hypertension and vascular injury [16-18]. When both neck and abdominal visceral fat are elevated, they increased the risk of arterial stiffness and dyslipidemia as compared to elevated abdominal visceral fat only [14].

Despite the advantages of NC as a simple, cheap, stable throughout the day, more feasible in cold weathers, and more acceptable in conservative communities -Middle East, Gulf countries-, also, it is more appropriate in morbidly obese, where the abdominal belly hinders accurate measurements of waist and hip circumferences, nevertheless, few studies have investigated its performance in Saudis. In addition, one of the shortcomings of a recent study is that the authors relied on reported risk factors to evaluate the performance of $\mathrm{NC}$ to predict cardiometabolic risks [19]. Hence, in the present study, we aim to explore the utility and applicability of NC to predict general and central obesity and MetS in a representative sample of adult Saudis of both genders using quantitative measures according to international guidelines.

\section{Methods}

The current study is a continuation of the cross-sectional Heart Health Promotion (HHP) study published previously [20]. HHP was conducted in Riyadh, Saudi Arabia, between 2013 and 2014 amongst King Saud University (KSU) employees and their families.

The initial study was approved by the Institutional Review Board (IRB) of the College of Medicine, University of King Saud (reference number 13-3721), and the study was conducted in accordance with the guidelines in the Declaration of Helsinki. All participants gave informed consent prior to enrollment in the study. Details of participants' recruitment and their characteristics have been described earlier [20].

Data were collected using a modified form of the "WHO STEPwise approach to chronic disease risk factor surveillance- Instrument-V2.1" (both Arabic and English Forms). This instrument uses sequential steps which include: questionnaire (Step1), anthropometric measurements (Step II), and biochemical measurements (Step III) [21].

\section{Study sample}

In this study, non-Saudis were excluded; the total sample size amounted to 3063 individuals of both genders. Considering obesity proportion of $25 \% \pm 0.05, p<0.01$, the power of the study using STATA/IC14.2 was $>0.9$.

\section{Anthropometric measurements}

NC was measured for all Participants, using a non-stretch Teflon, with increments down to $0.1 \mathrm{~cm}$. Participants were asked to stand erect with their head positioned at Frankfort horizontal plane. The superior border of a tape measure was placed just below the laryngeal prominence and applied perpendicular to the 
long axis of the neck. $\mathrm{NC}$ was obtained at a point just below the larynx (Adam's apple) and perpendicular to the long axis of the neck [22, 23].

Valid measures of central obesity including WC, hip circumference $(\mathrm{HC}), \mathrm{WHpR}$ and WHtR were estimated according to standardized techniques. The cutoff values used to diagnose central obesity based on $\mathrm{WC}$, and WHpR were: $\geq 102 \mathrm{~cm}$, and $\geq 0.9$ for males, and $\geq 88 \mathrm{~cm}$, and 0.85 for females respectively [24-26]. While the cutoff value of WHtR was $\geq 0.5$ for both genders [26].

BMI is defined as a measure of general obesity and was calculated as the ratio between weight $(\mathrm{kg})$ and squared height $\left(\mathrm{m}^{2}\right)$ Height was measured without shoes to the nearest $0.01 \mathrm{~m}$ on a stadiometer, and weight in kilogram was measured in light clothing on a level balance to the nearest $0.01 \mathrm{~kg}$. The balance was checked for accuracy at frequent intervals. Obesity was defined as $\mathrm{BMI} \geq 30 \mathrm{~kg} / \mathrm{m}^{2}$ [27].

\section{Definition of cardiometabolic risk factors Hypertension}

Participants were deemed hypertensive if they selfreported that they were currently using any anti-hypertensive medications regardless of their blood pressure readings. Participants were subsequently classified, as per the guideline in "The Seventh Report of the Joint National Committee (JNC7)" [28].

\section{Diabetes mellitus}

Participants were identified as having diabetes (type I or type II) if they reported current use of any diabetes medications, or reported a previous diagnosis of diabetes, or if their blood tests in this study showed any increase in a value HBA1C. Based on WHO and American Diabetes Association (ADA) criteria, participants were considered as having diabetes if the HBA1C level was $\geq 6.5 \%[29,30]$.

\section{Dyslipidemia}

Subjects were categorized as having any sort of dyslipidemia according to the WHO and the Third Adult Treatment Panel (ATP-III) of the National Cholesterol Education Program (NCEP). Dyslipidemia includes raised level of TC, and/or LDL-C, or/and TGs and low level of HDLC, or if the subject reported using medications to lower blood lipid levels [24, 31].

All Participants were asked to fast $12 \mathrm{~h}$ before undergoing for a blood draw to measure lipid profile and fasting plasma glucose. Also, HBA1C was performed to all participants.

\section{Metabolic syndrome (MetS)}

Participants were identified as having MetS according to the NCEP-ATPIII criteria which relies on at least three out of five factors namely; central obesity, elevated triglycerides, reduced HDL-Cholesterol (HDL-C), elevated blood pressure, and elevated fasting glucose [24].

\section{Statistical analysis}

Data were analyzed using SPSS ${ }^{\circ} 19$ (PASW statistics data document 19). Categorical data were summarized as frequency and percentages and were compared using Chi-square Goodness of fit test, while numeric data were summarized as means and standard deviations (SD), and were compared using independent sample t-test or Mann-Whitney-U test after testing for normality.

Receiver operating characteristic (ROC) analyses by gender were used to assess the accuracy of NC to predict general obesity, central obesity, and MetS in reference to valid indices (BMI as the gold slandered for general obesity, WHpR as the gold standard for central obesity, and NCEP-ATPIII criteria as the gold standard for MetS). Gender-specific NC cutoff values were estimated using the maximum value of the Youden's index which is defined as: "sensitivity + specificity -1" [13].

Odds ratio with $95 \% \mathrm{CI}$ were determined by multiple logistic regression analyses in models adjusted for age and WHtR as they provided the best model fit for the data. A $P$-value $<0.05$ was considered statistically significant.

\section{Results}

This study encompassed 3063 participants with a mean age of $38.6 \pm 14.1$ years, a minimum of 18 , and a maximum of 85 years. Table 1 depicts the characteristics of the study sample by gender, Female to male ratio was 1.65 , while their mean ages were comparable. Males had statistically higher values for the majority of anthropometric measurements, except the mean value of BMI was higher in females, and the proportion of obese females was $39.2 \%$ versus $33.1 \%$ in males. Males had statistically higher mean values than females for systolic blood pressure, diastolic blood pressure, most of the lipid profile, but the total cholesterol level and, the fasting blood glucose levels were statistically equal in both genders. More than two-thirds of males, and half of females had dyslipidemia, the difference was statistically significant. The results revealed no statistical difference in the proportions of diabetes, hypertension and MetS between genders.

In Table 2; we compared the performance of $\mathrm{NC}$ versus the other anthropometric indices according to gender, and diabetic status using ROC analyses to diagnose general obesity as based on BMI, and central obesity as based on WHpR according to WHO guidelines [32]. The AUCs of neck circumference possessed a good discriminating ability for general obesity, its value ranged from 0.82 to 0.84 . But, the performance of $\mathrm{WC}$ and WHtR exceeds that of NC as their computed AUCs ranged from 0.91 to 0.93 . Among diabetics, the performance of all the aforementioned indices was slightly 
Table 1 Characteristics of the Study Sample according to Gender

\begin{tabular}{|c|c|c|c|}
\hline & Males $(n=1156)$ & Females $(n=1907)$ & $P$ value \\
\hline Variables & Mean \pm SD & Mean \pm SD & \\
\hline Age in years & $38.00 \pm 14.34$ & $39.00 \pm 13.94$ & 0.068 \\
\hline Neck Circumference(cm) & $37.87 \pm 3.05$ & $33.35 \pm 3.05$ & $<0.001$ \\
\hline Waist Circumference (cm) & $90.20 \pm 14.58$ & $79.51 \pm 13.41$ & $<0.001$ \\
\hline Hip Circumference (cm) & $104.29 \pm 11.66$ & $106.25 \pm 12.21$ & $<0.001$ \\
\hline Waist/Height Ratio & $0.53 \pm 0.09$ & $0.50 \pm 0.09$ & $<0.001$ \\
\hline Waist/Hip Ratio & $0.86 \pm 0.09$ & $0.75 \pm 0.15$ & $<0.001$ \\
\hline $\mathrm{BMI}, \mathrm{kg} / \mathrm{m}^{2}$ & $28.20 \pm 5.99$ & $28.68 \pm 6.41$ & 0.047 \\
\hline $\mathrm{SBP}, \mathrm{mm} \mathrm{Hg}$ (average of 2 readings)^ & $122.00,17.00$ & $114.00,20.00$ & $<0.001$ \\
\hline DBP, mm Hg (average of 2 readings) & $73.70 \pm 12.78$ & $67.99 \pm 8.93$ & $<0.001$ \\
\hline $\mathrm{LDL}, \mathrm{mmol} / \mathrm{L}$ & $3.11 \pm 0.89$ & $3.02 \pm 0.80$ & 0.003 \\
\hline $\mathrm{TC}, \mathrm{mmol} / \mathrm{L}$ & $4.87 \pm 0.97$ & $4.92 \pm 0.91$ & 0.176 \\
\hline $\mathrm{TG}, \mathrm{mmol} / \mathrm{L}$ & $1.42 \pm 1.08$ & $1.09 \pm 0.65$ & $<0.001$ \\
\hline $\mathrm{HDL}, \mathrm{mmol} / \mathrm{L}$ & $1.13 \pm 0.29$ & $1.40 \pm 0.36$ & $<0.001$ \\
\hline Blood Glucose, mmol/L^ & $4.70,1.30$ & $4.70,1.00$ & 0.101 \\
\hline Obesity $\left(\mathrm{BM} 1 \geq 30 \mathrm{~kg} / \mathrm{m}^{2}\right)(\mathrm{n}, \%)$ & $283(33.10)$ & $747(39.20)$ & 0.001 \\
\hline Dyslipidemia (n,\%) & $805(70.40)$ & $1335(53.20)$ & $<0.001$ \\
\hline Diabetes Positives (n,\%) & $200(17.30)$ & 349 (18.30) & 0.484 \\
\hline Hypertension Positives $(n, \%)$ & $252(21.80)$ & $361(18.90)$ & 0.054 \\
\hline Metabolic Syndrome (n,\%) & $249(21.50)$ & $384(20.10)$ & 0.352 \\
\hline
\end{tabular}

Legend: $S D$ Standard Deviation, $n$ number, $\wedge$ skewed variables presented in median, Interquartile range and used Mann-Whitney test for comparison $B M I$ body mass index, SBP systolic blood pressure, DBP diastolic blood pressure, $T C$ total cholesterol, HDL high density lipoprotein cholesterol, $L D L$ low density lipoprotein Cholesterol, TAG triglycerides

attenuated. On whole, all indices had a slightly better performance among males. Of note, the WHpR ratio which measures central obesity, had the lowest values of AUCs as compared to other indices, furthermore, it failed to discriminate between obese and non-obese in diabetics.

Regarding central obesity, we included BMI which is used solely to estimate general obesity to highlight the difference between invalid and valid anthropometric indices. Overall, NC possessed a good discriminative ability, the AUCs were 0.80 and 0.77 for males and female respectively. However, the performance of $\mathrm{WC}$ and WHtR exceeds that of NC. Nevertheless, the discriminative ability of $\mathrm{NC}, \mathrm{WC}$ and WHtR was lower than that for general obesity, with further attenuation in diabetics. Among all indices, NC was the only one which holds its consistency as a better measurement among males. As expected, BMI had the least discriminative ability, furthermore, it failed to discriminate between obese and non-obese in diabetics (Table 2).

In MetS, the AUCs of the NC equaled that of WHpR: 0.77 , and 0.82 versus 0.77 , and 0.83 for males, and females respectively. But the AUCs of WC and WHtR were slightly larger than that of NC. The AUC of BMI for males was the least of all indices (0.75) (Table 3).
We estimated the best cutoff values of NC to predict obesity and metabolic syndrome using Youden's index. In males, the best cutoff value of NC was $\geq 37.5 \mathrm{~cm}$, versus $\geq 32.5 \mathrm{~cm}$ for females. Using these cutoffs, both NPVs and sensitivities exceeded $85 \%$ across all categories; hence, we can rule-out obesity when the result is negative with a great precision. However, the value of $\mathrm{NC}$ to rule-in obese individuals was moderate according to the estimates of PPVs and specificities (Table 4).

Table 5 shows the results of logistic regression analysis, after adjusting for age, and WHtR. Results revealed consistent positive associations; the strength of association was the highest for general obesity, followed by MetS. In males, ORs were 4.26 , and 3.03 , which were analogous to ORs in females being 4.65, and 3.66 for obesity, and MetS respectively. Regarding central obesity, ORs were still positive- 1.47 and 1.45 for males and females respectively-, but the strength of association was weak, 95\% CI was (1.02-2.08), and (0.95-2.26) for males and females respectively.

\section{Discussion}

We conducted the present study to explore the utility and applicability of NC to diagnose obesity and MetS among a segment of adult Saudis that represents the age group at 
Table 2 Area under the Curve (AUC) by Anthropometric Indices for General, and Central Obesity among Adult Saudis according to Gender, and Diabetic Status

\begin{tabular}{|c|c|c|c|c|}
\hline & \multicolumn{4}{|l|}{$\mathrm{AUC}(\mathrm{Cl} 95 \%)$} \\
\hline & $\mathrm{NC}$ & WC & $\mathrm{WHtR}$ & WHpR \\
\hline \multicolumn{5}{|c|}{ Obesity (Diabetics and non-diabetics) } \\
\hline Males (1156) & $0.84(0.82-0.87)$ & $0.92(0.90-0.93)$ & $0.92(0.90-0.94)$ & $0.70(0.67-0.73)$ \\
\hline Females (1907) & $0.83(0.81-0.85)$ & $0.91(0.89-0.92)$ & $0.91(0.90-0.92)$ & $0.69(0.67-0.72)$ \\
\hline \multicolumn{5}{|c|}{ Obesity (Non-diabetics) } \\
\hline Males (956) & $0.86(0.83-0.88)$ & $0.93(0.91-0.95)$ & $0.93(0.91-0.95)$ & $0.71(0.68-0.75$ \\
\hline Females (1556) & $0.82(0.80-0.84)$ & $0.91(0.90-0.92)$ & $0.91(0.90-0.93)$ & $0.68(0.66-0.71)$ \\
\hline \multicolumn{5}{|c|}{ Obesity (Diabetics) } \\
\hline Males (200) & $0.77(0.70-0.83)$ & $0.88(0.83-0.93)$ & $0.91(0.87-0.95)$ & $0.62(0.52-0.68)$ \\
\hline \multirow[t]{2}{*}{ Females (348) } & $0.77(0.72-0.83)$ & $0.84(0.80-0.88)$ & $0.85(0.81-0.89)$ & $0.52(0.45-0.58)^{\wedge}$ \\
\hline & NC & WC & $\mathrm{WHtR}$ & $\mathrm{BMI}$ \\
\hline \multicolumn{5}{|c|}{ Central Obesity (Diabetics and Non-Diabetics) } \\
\hline Males (1156) & $0.80(0.77-0.82)$ & $0.88(0.86-0.90)$ & $0.89(0.87-0.91)$ & $0.75(0.72-0.78)$ \\
\hline Females (1907) & $0.77(0.74-0.80)$ & $0.90(0.88-0.92)$ & $0.90(0.82-0.92)$ & $0.70(0.67-0.73)$ \\
\hline \multicolumn{5}{|c|}{ Central Obesity (Non-diabetics) } \\
\hline Males (956) & $0.79(0.76-0.82)$ & $0.88(0.86-0.90)$ & $0.89(0.91-0.95)$ & $0.72(0.72-0.78)$ \\
\hline Females (1556) & $0.78(0.74-0.82)$ & $0.91(0.88-0.93)$ & $0.92(0.89-0.94)$ & $0.71(0.67-0.75)$ \\
\hline \multicolumn{5}{|c|}{ Central Obesity (Diabetics) } \\
\hline Males (200) & $0.71(0.61-0.81)$ & $0.81(0.72-0.89)$ & $0.82(0.74-0.91)$ & $0.64(0.53-0.76)$ \\
\hline Females (348) & $0.60(0.54-0.67)$ & $0.78(0.73-0.83)$ & $0.78(0.73-0.82)$ & $0.50(0.44-0.57) \wedge$ \\
\hline
\end{tabular}

Legend: $N C$ neck circumference, $W C$ waist circumference, $W H t R$ waist height ratio, $W H p R$ waist hip ratio, $B M I$ body mass index $\wedge=$ not significant, $C I C$ Confidence Interval

high risk. The study encompassed a fairly large sample size amounted to 3063 individuals of both genders.

Our results demonstrated that the estimated cutoff values of $\mathrm{NC}$ for males and females were independently associated with general and central obesity, as well as with MetS after adjustment of relevant confounders. However, the strength of association was maximized for general obesity and MetS.

This study provides an additional indicator of the good performance of $\mathrm{NC}$ to predict general obesity in two ways. First, among non-diabetics, the AUCs of the ROC analyses ranged from $0.82-0.86$. Second, the estimated neck cutoff values revealed high sensitivity and NPV across all categories of participants which ranged from 86 to $96 \%$, and $80.5-91 \%$ for sensitivity and NPV respectively. Thus, we can rule-out obesity when the result is negative with a great precision. Accordingly, the utility of NC as a screening tool for general obesity is ascertained. In agreement with our results, several studies confirmed the validity of $\mathrm{NC}$ as a good measure of obesity, since it is correlated positively with WC, WHtR, and BMI [12-14].

In comparison to general obesity, the performance of $\mathrm{NC}$ to predict central obesity was slightly attenuated. This observation is expected because NC reflects UBSF [16-18]. Meanwhile, the attributes of the impaired diagnostic capability of NC as well as WC and WHtR in diabetics might be linked to the disease process which affects the dynamics of fat metabolism. However, further validation of $\mathrm{NC}$ among diabetics needs further investigation using a large sample size and a sensitive quantitative technique for the accurate estimation of body fat. In accordance with our results, several studies reported similar performance of $\mathrm{NC}$ to predict central obesity based on the ROC analyses which demonstrated values of AUCS comparable to our results [33-35].

Table 3 Area under the curve (AUC) by Anthropometric Indices for Metabolic Syndrome among Adult Saudis According to Gender

\begin{tabular}{llllll}
\hline & AUC $(95 \% \mathrm{Cl})$ & & & \\
\cline { 2 - 6 } & NC & WC & WHtR & WHpR & BMl \\
\hline Males (1156) & $0.77(0.74-0.81)$ & $0.81(0.78-0.84)$ & $0.81(0.78-0.84)$ & $0.77(0.74-0.80)$ & $0.75(0.72-0.78)$ \\
Females (1907) & $0.82(0.80-0.84)$ & $0.88(0.87-0.90)$ & $0.89(0.87-0.91$ & $0.83(0.81-0.85)$ & $0.81(0.79-0.84)$ \\
\hline
\end{tabular}

Legend: NC neck circumference, WC waist circumference, WHtR waist height ratio, WHPR waist hip ratio, BMI body mass index 
Table 4 Neck Circumference Cutoff Values to Diagnose General Obesity in Adult Saudis According to Gender and Diabetic Status

\begin{tabular}{lllll}
\hline & Sensitivity\% & Specificity\% & PPV\% & NPV\% \\
\hline Total & & & & \\
Male: N1156 & 86.4 & 64.2 & 54.4 & 90.5 \\
Female: N 1907 & 88.9 & 61.3 & 59.7 & 89.5 \\
Non-diabetics & & & & \\
Male: N 956 & 84.9 & 69.4 & 55.8 & 91.0 \\
Female: N 1558 & 85.5 & 65.1 & 54.8 & 90.0 \\
Diabetics & & & & \\
Male: N 200 & 91.7 & 34.5 & 50.3 & 85.1 \\
Female: N 349 & 96.5 & 28.0 & 72.4 & 80.5 \\
\hline
\end{tabular}

Legend: NC cutoff to diagnose obesity for males $=37.5 \&$ for females is 32.5 , $P P V$ positive predictive value, NPV negative predictive value

Despite the fact that the performance of $\mathrm{WC}$ and $\mathrm{WHtR}$ exceeds that of $\mathrm{NC}$ to diagnose both types of obesity, yet NC might be efficient for several reasons. First, it might be more culturally acceptable in the Gulf region. Second, compared to WC and WHtR, its performance is stable between genders for both central and general obesity. Third, its stability is not affected by physical, or physiological conditions; in contrast, WC is affected by being full or hungry, respiratory movement, and wearing heavy clothing. In addition, the inter and intra-rater reliability of $\mathrm{NC}$ is high, with no need for multiple measurements [36] .

Regarding the MetS, as one might expect that WC, WHtR and WHpR as indices of visceral obesity would be better discriminators. Nevertheless, this study demonstrated that NC was comparable to WC and WHtR, and was almost identical to WHpR to predict MetS. Furthermore, a large Brazilian study confirmed that NC correlated positively with all known risk factors of MetS, and negatively with protective factors including insulin sensitivity and high-density lipids [37]. In addition, a recent study claimed that, in morbidly obese individuals, $\mathrm{NC}$ was even better than WC to assess the metabolic health [38].

Table 5 Gender Specific Odds Ratio of Obesity and Metabolic Syndrome, for Neck Circumference among Adult Saudis

\begin{tabular}{lll}
\hline Variables & Adjusted OR & $95 \% \mathrm{Cl}$ \\
\hline General obesity & & \\
Males & 4.26 & $2.95-6.15$ \\
Females & 4.65 & $3.43-6.29$ \\
Central Obesity & & \\
Males & 1.45 & $1.02-2.08$ \\
Females & 1.47 & $0.95-2.26$ \\
Metabolic syndrome & & \\
Males & 3.03 & $2.95-6.15$ \\
Females & 3.66 & $2.35-5.69$ \\
\hline
\end{tabular}

Legend: OR Odds Ration, Adjusted for age, and WHtR, Cl confidence interval
We computed the NC cutoffs for both males and females which better discriminates between obese and non-obese. The dissimilarities of NC cutoff values between different studies; for example Chinese, Brazilian, and Turkish [13, 35, 37, 39] indicates that ethnic-specific cutoffs are essential, and it should be estimated based on large sample size to ensure generalizability of the study results. However a recent study from Saudi Arabia reported higher cutoff values in both mlaes and females; this variability might be related to the variations in sample size, characteristics of study participants and in the methodology used to determine the optimal cutoff; while we based our estimation on Youden's index to determine the cutoff value for both general and central obesity [13]; in the aforementioned study, the authors reported the cutoff values for central obesity and it was not clear how the authors determined the selected values [19].

Finally, we used regression analysis to delineate the strength of association between NC, MetS and both general and central obesity for males and females separately after adjusting for age and WHtR. In both genders, ORs were very close, Therefore, we can exclude the effect modification due to gender. The strength of association was maximized for general obesity and MetS $(\mathrm{OR}>3)$ which is more than double that for central obesity. Several studies considered $\mathrm{NC}$ as a novel single predictor of MetS [34, 35, 39]. Another Chinese study which included about 2000 adults of both genders concluded that $\mathrm{NC}$ has a power analogous to WC to identify metabolic disorders [40]. Furthermore, several studies confirmed that NC correlated positively with free fatty acids, insulin resistance, very-low-density lipoprotein cholesterol, oxidative stress, endothelial cell damage, hypertension and vascular injury, and was inversely correlated with HDL-C $[16-18,39]$. In the present study, the uncertainty of NC to predict central obesity is logical, since $\mathrm{NC}$ is a measure of upper- body fat. This observation further confirms that NC predicts MetS beyond central obesity [41].

\section{Limitations}

The convenient sampling technique and the cross-sectional study design might affect the generalizability of results. But, the large sample size with a power exceeding 0.9 and the completed documentations of all studied variables with no missing values could compensate for these limitations.

\section{Conclusion}

ROC analyses demonstrated a good discriminative power of NC to predict obesity and metabolic syndrome. Furthermore, NC stands out as an independent predictor of general obesity and the MetS using cutoff values of $\geq 37.5$ for men, and $\geq 32.5$ for women. 
Its stability, ease of application, low cost and the cultural consideration justify its use as a screening tool for general obesity and MetS among Saudis under community settings, and as an additional routine measurement for health professionals.

\section{Abbreviations}

ATP-III: Third Adult Treatment Panel; AUC: Area under the curve; BMI: Body mass index; Cl: Confidence Interval; CT: Computed Tomography; CVDs: Cardiovascular diseases; CVRF: Cardiovascular risk factors; HbA1C: Glycosylated hemoglobin; HDL-C: High density lipoprotein cholesterol; LDL-C: low density lipoprotein cholesterol; MetS: Metabolic Syndrome; NC: Neck Circumference; NCEP: National Cholesterol Education Program; NPV: Negative predictive value; OR: Odds Ratio; PPV: Positive predictive value; ROC: Receiver operating characteristic curve; TC: Total cholesterol; TG: Triglycerides; WC: Waist circumference; WHpR: Waist hip ratio: WHtR: Waist Height Ratio

\section{Acknowledgements}

We would like to express our appreciation to all participants in this study, they offered their time to respond to questionnaires, perform clinical and laboratory assessment as required.

\section{Funding}

This study was supported by the College of Medicine Research Center, deanship of scientific research, King Saud University. The funder had no role in study design, data collection, data analysis, decision to publish or preparation of the manuscript

\section{Availability of data and materials}

Data are available from the Ethics Committee of King Saud University, College of Medicine for researchers who meet the criteria for access to confidential data. Data will be available upon request, for that purpose kindly contact RA at ras_zeidan@hotmail.com.

\section{Authors' contributions}

All authors (RA, AF, AH and HE) were responsible for study conception, design, analysis plan and funding acquisition. RA was responsible for study implementation. RA and HE drafted the manuscript, HE analyzed the data, AF participated in statistical analysis. All members of the team read the final draft of the manuscript and approved it.

\section{Ethics approval and consent to participate}

The study was approved by the Institutional Review Board (IRB) of the College of Medicine, University of King Saud (reference number 13-3721), the study was conducted in accordance with the guidelines in Helsinki Declaration and all participants gave informed written consent prior to enrollment in the study.

\section{Consent for publication \\ Not applicable.}

\section{Competing interests}

The authors declare that they have no competing interests.

\section{Publisher's Note}

Springer Nature remains neutral with regard to jurisdictional claims in published maps and institutional affiliations.

\section{Author details}

'Cardiac Sciences Department Riyadh, King Saud University, College of Medicine, Riyadh, Saudi Arabia. ${ }^{2}$ College of Medicine, Princess Nourah bint Abdulrahman University, Riyadh, Saudi Arabia. ${ }^{3} \mathrm{High}$ Institute of Public Health, Alexandria University, Alexandria, Egypt.
Received: 25 July 2018 Accepted: 21 February 2019

Published online: 01 April 2019

\section{References}

1. Swinburn BA, Sacks G, Hall KD, McPherson K, Finegood DT, Moodie ML, Gortmaker SL. The global obesity pandemic: shaped by global drivers and local environments. Lancet. 2011;378(9793):804-14.

2. Rivera JA, de Cossio TG, Pedraza LS, Aburto TC, Sanchez TG, Martorell R. Childhood and adolescent overweight and obesity in Latin America: a systematic review. Lancet Diabetes Endocrinol. 2014;2(4):321-32.

3. Ogden $\mathrm{CL}$, Carroll MD, Kit BK, Flegal KM. Prevalence of obesity among adults: United States. NCHSData Brief. 2011-2012;2013(131):1-8.

4. Gee S, Chin D, Ackerson L, Woo D, Howell A. Prevalence of childhood and adolescent overweight and obesity from 2003 to 2010 in an integrated health care delivery system. J Obes. 2013:2013:417907.

5. al-Nuaim AR, Mirdad S, al-Rubeaan K, al-Mazrou Y, al-Attas O, al-Daghari N, Khoja T. Population-based epidemiological study on characteristics of risk factors of hypercholesterolemia in Saudi Arabia. Int J Cardiol. 1997;62(1):47-54.

6. DeNicola E, Aburizaiza OS, Siddique A, Khwaja H, Carpenter DO. Obesity and public health in the Kingdom of Saudi Arabia. Rev Environ Health. 2015; 30(3):191-205

7. Memish ZA, El Bcheraoui C, Tuffaha M, Robinson M, Daoud F, Jaber S, Mikhitarian S, Al Saeedi M, AlMazroa MA, Mokdad AH, et al. Obesity and associated factors--Kingdom of Saudi Arabia, 2013. Prev Chronic Dis. 2014; 11:E174

8. Alhyas L, McKay A, Balasanthiran A, Majeed A. Prevalences of overweight, obesity, hyperglycaemia, hypertension and dyslipidaemia in the Gulf: systematic review. JRSMShort Rep. 2011;2(7):55.

9. Ng SW, Zaghloul S, Ali HI, Harrison G, Popkin BM. The prevalence and trends of overweight, obesity and nutrition-related non-communicable diseases in the Arabian Gulf States. ObesRev. 2011;12(1):1-13.

10. WHO: Waist circumference and waist-hip ratio: Report of a WHO expert consultation, Geneva, 8-11. 2008. http://apps.who.int/iris/bitstream/10665/ 44583/1/9789241501491_eng.pdf, 2011 date of aceess 11 Nov.2017.

11. NHLBI: National Obesity Education Initiative of the National Heart, Lung, and Blood Institute (NHLBI). Clinical Guidelines on the Identification, Evaluation, and Treatment of Overweight and Obesity in Adults: The Evidence Report. Bethesda, MD: National Institutes of Health, 1998. The Evidence Report Bethesda, MD: National Institutes of Health; 1998.

12. Ferretti Rde L, Cintra Ide P, Passos MA, de Moraes Ferrari GL, Fisberg M. Elevated neck circumference and associated factors in adolescents. BMC Public Health. 2015;15:208.

13. Yang GR, Yuan SY, Fu HJ, Wan G, Zhu LX, Bu XL, Zhang JD, Du XP, Li YL, J $Y$, et al. Neck circumference positively related with central obesity, overweight, and metabolic syndrome in Chinese subjects with type 2 diabetes: Beijing community diabetes Study 4. Diabetes Care. 2010;33(11): 2465-7.

14. Fantin F, Comellato G, Rossi AP, Grison E, Zoico E, Mazzali G, Zamboni M. Relationship between neck circumference, insulin resistance and arterial stiffness in overweight and obese subjects. Eur J Prev Cardiol. 2017;24(14): $1532-40$.

15. Guo X, Li Y, Sun G, Yang Y, Zheng L, Zhang X, Sun Z, Ma H, Wang N, Jiang $\mathrm{M}$, et al. Prehypertension in children and adolescents: association with body weight and neck circumference. Intern Med. 2012;51 (1):23-7.

16. Sjostrom CD, Hakangard AC, Lissner L, Sjostrom L. Body compartment and subcutaneous adipose tissue distribution--risk factor patterns in obese subjects. Obes Res. 1995;3(1):9-22.

17. Cizza G, de Jonge L, Piaggi P, Mattingly M, Zhao X, Lucassen E, Rother Kl, Sumner AE, Csako G, Study NSE. Neck circumference is a predictor of metabolic syndrome and obstructive sleep apnea in short-sleeping obese men and women. Metab Syndr Relat Disord. 2014;12(4):231-41.

18. Horska K, Kucerova J, Suchy P, Kotolova H. Metabolic syndrome dysregulation of adipose tissue endocrine function. Ceska Slov Farm. 2014 63(4):152-9.

19. Alfadhli EM, Sandokji AA, Zahid BN, Makkawi MA, Alshenaifi RF, Thani TS, Habeeb HA. Neck circumference as a marker of obesity and a predictor of cardiometabolic risk among Saudi subjects. Saudi medical journal. 2017; 38(12):1219-23.

20. Alzeidan R, Rabiee F, Mandil A, Hersi A, Fayed A. Non-communicable disease risk factors among employees and their families of a Saudi University: an epidemiological Study. PLoS One. 2016;11(11):e0165036. 
21. Noncommunicable diseases and their risk factors [http://www.who.int/ncds/ surveillance/steps/instrument/en/].

22. Martinho FL, Tangerina RP, Moura SM, Gregorio LC, Tufik S, Bittencourt LR. Systematic head and neck physical examination as a predictor of obstructive sleep apnea in class III obese patients. BrazJ Med BiolRes. 2008; 41(12):1093-7.

23. Davidson TM, Patel MR. Waist circumference and sleep disordered breathing. Laryngoscope. 2008;118(2):339-47.

24. US NCEP A III. Third report of the National Cholesterol Education Program (NCEP) expert panel on detection, evaluation, and treatment of high blood cholesterol in adults (adult treatment panel III) final report. Circulation. 2002; 106(25):3143-421.

25. Grundy SM, Cleeman JI, Daniels SR, Donato KA, Eckel RH, Franklin BA, Gordon DJ, Krauss RM, Savage PJ, Smith SC Jr, et al. Diagnosis and management of the metabolic syndrome: an American Heart Association/ National Heart, Lung, and Blood Institute scientific statement. CurrOpinCardiol. 2006;21(1):1-6.

26. Browning LM, Hsieh SD, Ashwell M. A systematic review of waist-to-height ratio as a screening tool for the prediction of cardiovascular disease and diabetes: 0.5 could be a suitable global boundary value. NutrResRev. 2010; 23(2):247-69.

27. Global Database on Boday Mass Index [http://apps.who.int/bmi/index. jsp?introPage=intro_3.html].

28. Chobanian AV, Bakris GL, Black HR, Cushman WC, Green LA, Izzo JL Jr, Jones DW, Materson BJ, Oparil S, Wright JT Jr, et al. Seventh report of the joint National Committee on prevention, detection, evaluation, and treatment of high blood pressure. Hypertension. 2003;42(6):1206-52.

29. Use of Glycated Haemoglobin (HbA1c) in the Diagnosis of Diabetes: abberviated report of WHO consultation .WHO: Geneva 2011 Mellitus:http:// www.who.int/diabetes/publications/report-hba1c_2011.pdf

30. ADA. American Daibetes association:diagnosis and calssification of diabetes mellitus. Diabetes Care. 2010;33:562-9.

31. Gordon DJ, Probstfield JL, Garrison RJ, Neaton JD, Castelli WP, Knoke JD, Jacobs DR Jr, Bangdiwala S, Tyroler HA. High-density lipoprotein cholesterol and cardiovascular disease. Four prospective American studies. Circulation. 1989;79(1):8-15.

32. World Health Organization. World Health Report: The World Health Report 2008 - primary Health Care (Now More Than Ever). Available online: https:// www.who.int/whr/2008/en/. Accessed 25 Feb 2019.

33. Preis SR, Pencina MJ, D'Agostino RB Sr, Meigs JB, Vasan RS, Fox CS. Neck circumference and the development of cardiovascular disease risk factors in the Framingham heart Study. Diabetes Care. 2013;36(1):e3.

34. Preis SR, Massaro JM, Hoffmann U, D'Agostino RB Sr, Levy D, Robins SJ, Meigs JB, Vasan RS, O'Donnell CJ, Fox CS. Neck circumference as a novel measure of cardiometabolic risk: the Framingham heart study. J Clin Endocrinol Metab. 2010;95(8):3701-10.

35. Onat A, Hergenc G, Yuksel H, Can G, Ayhan E, Kaya Z, Dursunoglu D. Neck circumference as a measure of central obesity: associations with metabolic syndrome and obstructive sleep apnea syndrome beyond waist circumference. Clinical nutrition (Edinburgh, Scotland). 2009:28(1):46-51.

36. LaBerge RC, Vaccani JP, Gow RM, Gaboury I, Hoey L, Katz SL. Inter- and intra-rater reliability of neck circumference measurements in children. Pediatr Pulmonol. 2009:44(1):64-9.

37. Stabe C, Vasques AC, Lima MM, Tambascia MA, Pareja JC, Yamanaka A, Geloneze B. Neck circumference as a simple tool for identifying the metabolic syndrome and insulin resistance: results from the Brazilian metabolic syndrome Study. Clin Endocrinol. 2013;78(6):874-81.

38. Assyov Y, Gateva A, Tsakova A, Kamenov Z. A comparison of the clinical usefulness of neck circumference and waist circumference in individuals with severe obesity. Endocr Res. 2017;42(1):6-14.

39. Zhou JY, Ge H, Zhu MF, Wang L, Chen L, Tan YZ, Chen YM, Zhu HL. Neck circumference as an independent predictive contributor to cardio-metabolic syndrome. Cardiovasc Diabetol. 2013;12:76.

40. Luo Y, Ma X, Shen Y, Xu Y, Xiong Q, Zhang X, Xiao Y, Bao Y, Jia W. Neck circumference as an effective measure for identifying cardio-metabolic syndrome: a comparison with waist circumference. Endocrine. 2017;55(3):822-30.

41. Vallianou NG, Evangelopoulos AA, Bountziouka V, Vogiatzakis ED, Bonou MS, Barbetseas J, Avgerinos PC, Panagiotakos DB. Neck circumference is correlated with triglycerides and inversely related with $\mathrm{HDL}$ cholesterol beyond BMI and waist circumference. Diabetes Metab Res Rev. 2013;29(1):90-7.

Ready to submit your research? Choose BMC and benefit from:

- fast, convenient online submission

- thorough peer review by experienced researchers in your field

- rapid publication on acceptance

- support for research data, including large and complex data types

- gold Open Access which fosters wider collaboration and increased citations

- maximum visibility for your research: over $100 \mathrm{M}$ website views per year

At BMC, research is always in progress.

Learn more biomedcentral.com/submissions 